UCRL-JC-121817

PREPRINT

CONF-9505264-29

\title{
Fault Tolerance of the NIF Power Conditioning System
}

\author{
RECEIVED \\ OCT 111995 \\ OSTI
}

\author{
D. W. Larson, LLNL \\ R. Anderson, American Control Engineering \\ J. Boyes, SNL
}

This paper was prepared for submittal to the 1st Annual International Conference on Lasers for Application to Inertial Confinement Fusion Monterey, CA

May 30 - June 2, 1995

July 7, 1995

This is a preprint of a paper intended for publication in a journal or proceedings. Since changes may be made before publication, this preprint is made available with the understanding that it will not be cited or reproduced without the permission of the author.

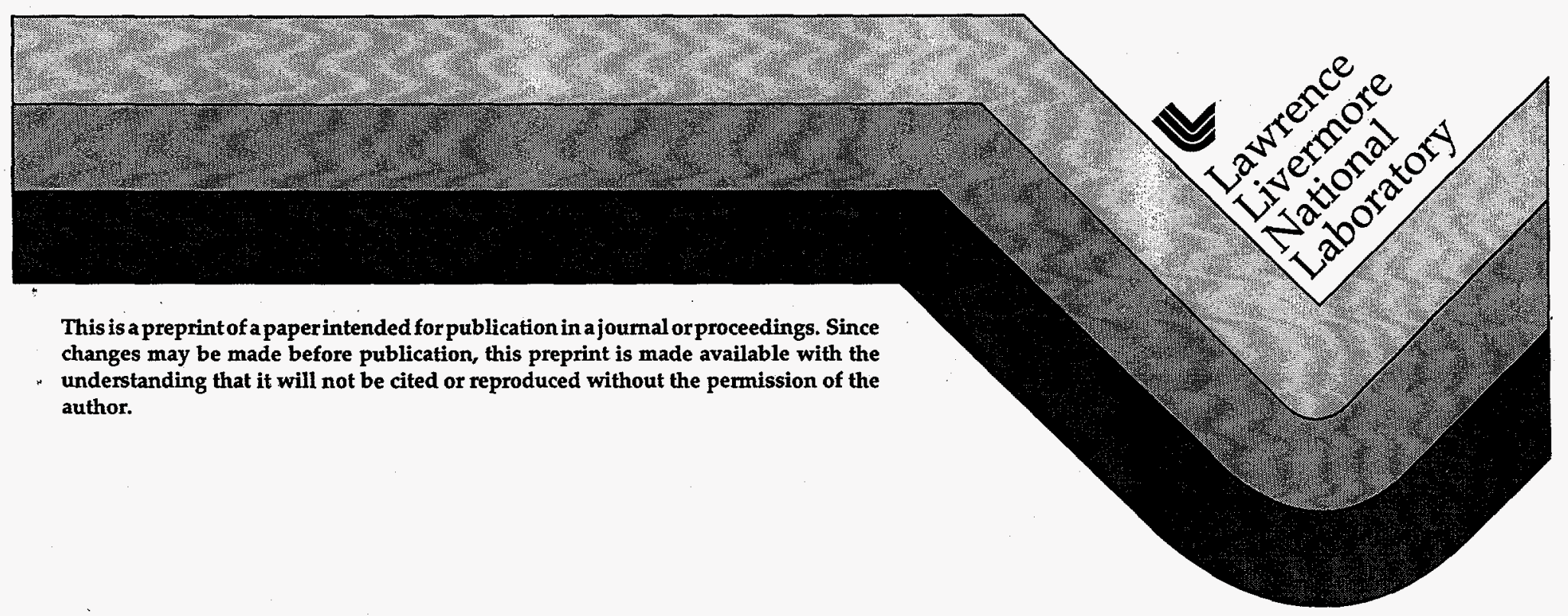




\section{DISCLAIMER}

This document was prepared as an account of work sponsored by an agency of the United States Government. Neither the United States Government nor the University of California, nor any of their employees makes any warranty, express or implied, or assumes any legal liability or responsibility for the accuracy, completeness, or usefulness of any information, apparatus, product, or process disclosed, or represents that its use would not infringe privately owned rights. Reference herein to any specific commercial products, process, or service by trade name, trademark, manufacturer, or otherwise, does not necessarily constitute or imply its endorsement, recommendation, or favoring by the United States Government or the University of California. The views and opinions of authors expressed herein do not necessarily state or reflect those of the United States Government or the University of California, and shall not be used for advertising or product endorsement purposes. 


\section{DISCLAIMER}

Portions of this document may be illegible in electronic image products. Images are produced from the best available original document. 


\title{
Fault Tolerance of the NIF Power Conditioning System
}

\author{
D. Larson, LLNL, R. Anderson, American Control Engineering \\ J. Boyes, SNL
}

\section{Summary}

The tolerance of the circuit topology proposed for the National Ignition Facility (NIF) power conditioning system to specific fault conditions is investigated. A new pulsed power circuit is proposed for the NIF which is simpler and less expensive than previous ICF systems. The inherent fault modes of the new circuit are different from the conventional approach, and must be understood to ensure adequate NIF system reliability. A test-bed which simulates the NIF capacitor module design was constructed to study the circuit design. Measurements from test-bed experiments with induced faults are compared with results from a detailed circuit model. The model is validated by the measurements and used to predict the behavior of the actual NIF module during faults. The model can be used to optimize fault tolerance of the NIF module through an appropriate distribution of circuit inductance and resistance. The experimental and modeling results are presented, and fault performance is compared with the ratings of pulsed power components. Areas are identified which require additional investigation.

\section{Introduction}

The NIF laser requires a $320 \mathrm{MJ}$ power conditioning system to drive the 7600 large Xenon flashlamps in the power amplifiers. The system consists of 200 modules which each store $1.6 \mathrm{MJ}$ and drive approximately 40 flashlamps arranged in 20 parallel series-pairs. The power flow of one module is shown in Figure 1.

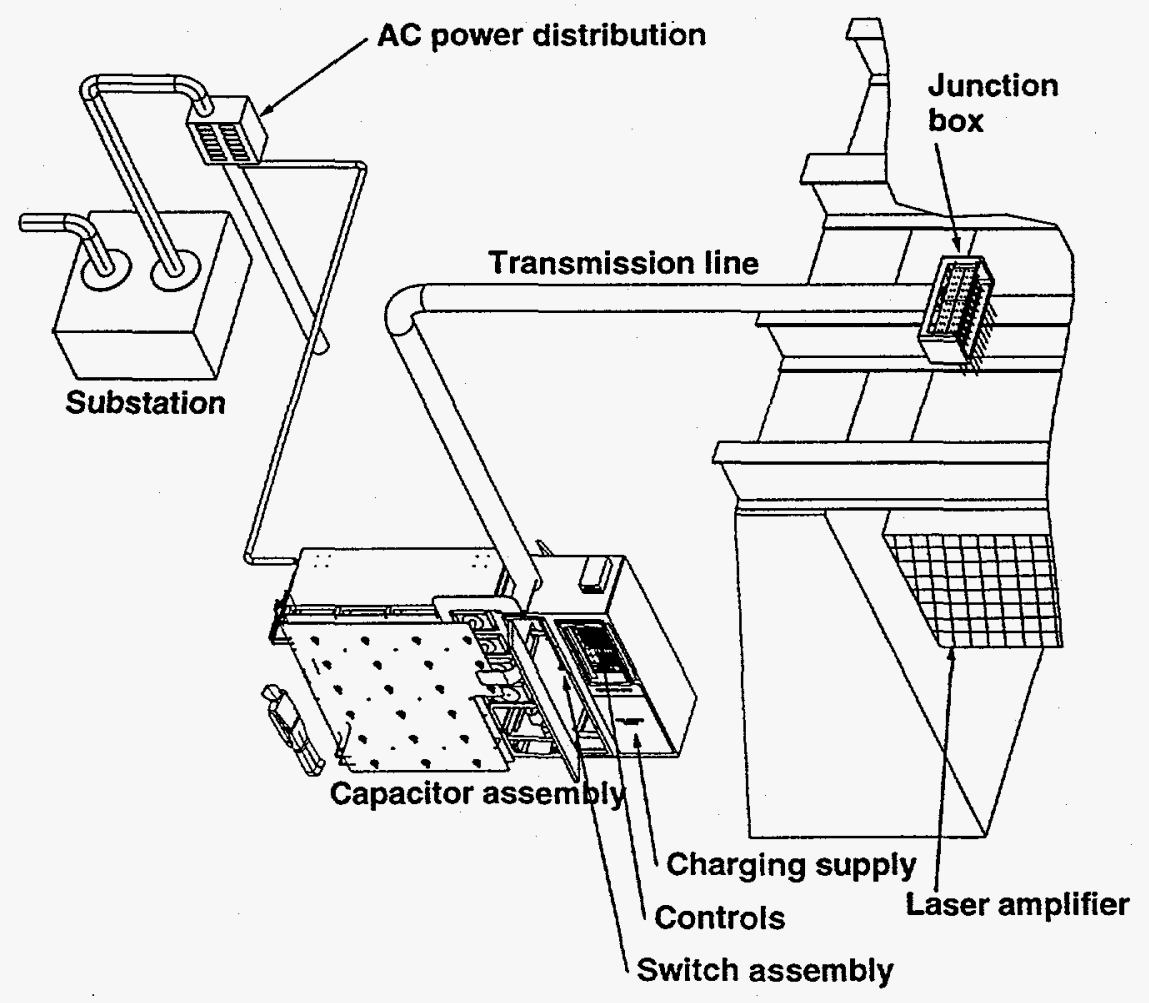

Conceptual power conditioning module layout 
Figure 2 illustrates the compact design of the NIF module. The capacitors, switches, preionization hardware, charging supplies and control system share a common mounting structure and enclosure. Independence among modules is assured since a single primary power line feeds the module and all control connections are via fiber optics. A single large transmission line delivers the $500 \mathrm{kA}, 360$ us output pulse to the flashlamps. The pulse is distributed among the 20 flashlamp pairs by ballast inductors in a junction box near the laser amplifier. The nominal capacitor charge voltage is $23.5 \mathrm{kV}$.

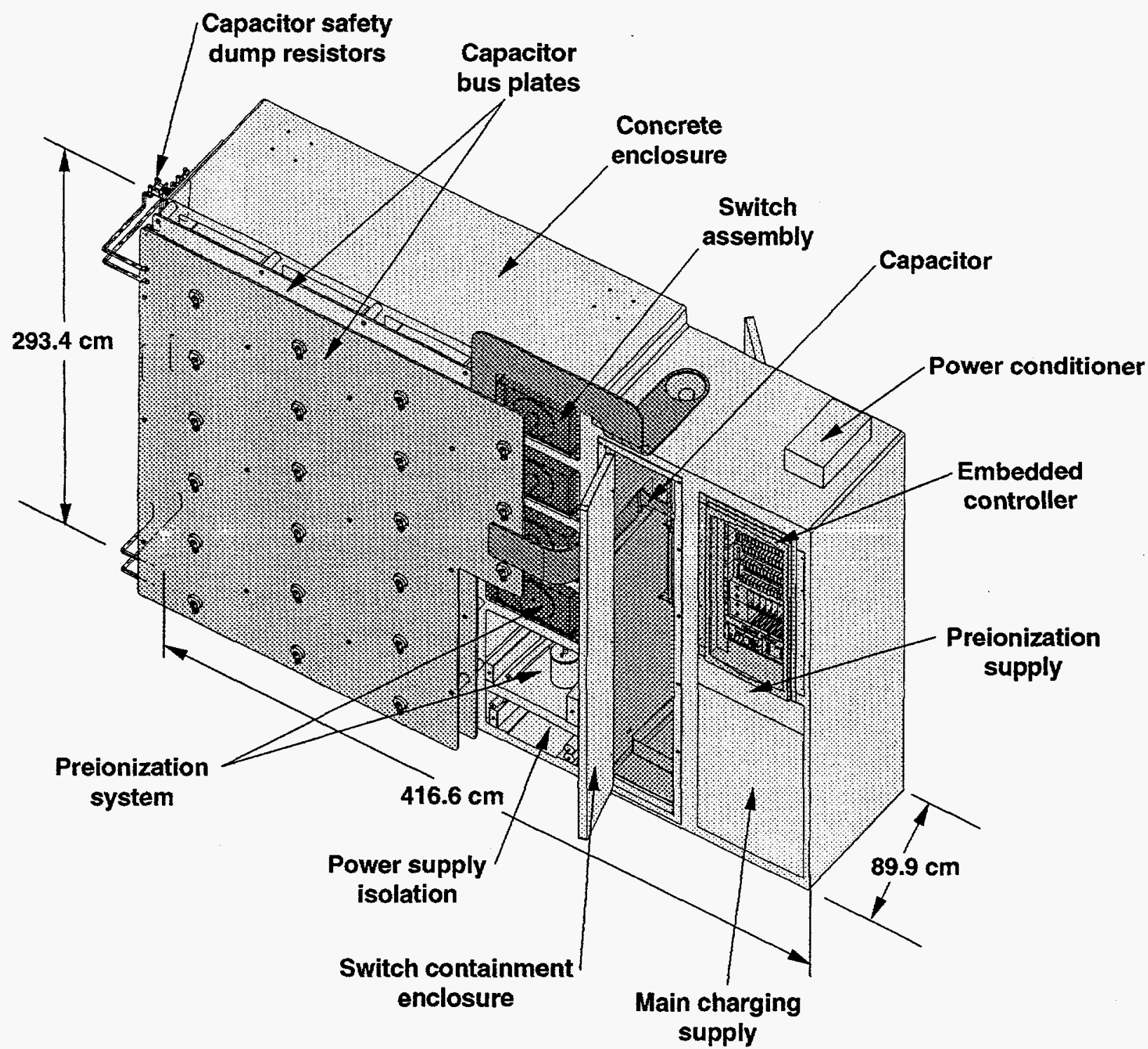

40-00-0394-0765pb01

This circuit approach, shown schematically in Figure 3, represents a cost savings of roughly $20 \%$ compared with previous systems such as LLNL's Nova laser ${ }^{1}$ which use individual pulse-forming-networks and output cables for each flashlamp circuit. The savings result from the reduced number of components and simpler assembly. Single-bushing capacitors, used in the NIF circuit are less expensive than dual-bushing capacitors required in previous systems. Charge and safety dump resistors previously required for each circuit are 
eliminated. The simple, compact design minimizes assembly cost by reducing the cable installation and termination labor required.

\section{NIF capacitor module}

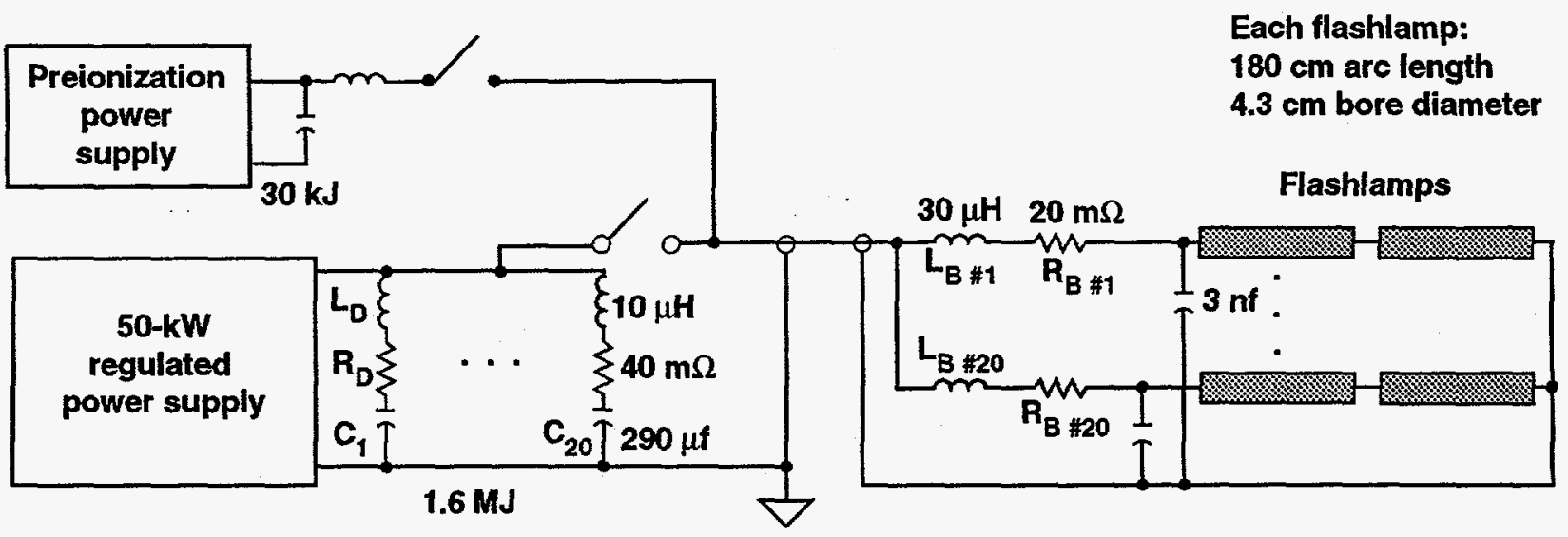

$70-50-0195-0234 p b 01$

The parallel circuit topology presents different fault modes than previous designs which must be accounted for in order to minimize the impact of circuit faults on the system reliability. The fault conditions of primary concern are summarized in Table 1. Ten years of Nova operating experience support the predicted frequency of the fault modes.

We are primarily concerned with three fault modes

\begin{tabular}{|l|l|l|l|l|}
\hline \multicolumn{1}{|c|}{ Fault } & Fault mode & \multicolumn{1}{|c|}{ Failure concerns } & Expected frequency & Nova failure rates \\
\hline Flashlamp fault & Short-circuit & $\begin{array}{l}\text { Neighboring flashlamps } \\
\text { Amplifiers blast-shield } \\
\text { Amplifier contamination } \\
\text { Ballast inductors }\end{array}$ & Several per year & 3 per year \\
\hline Capacitor fault & Short-circuit & $\begin{array}{l}\text { Neighboring capacitors } \\
\text { Damping resistors } \\
\text { Capacitor bus work }\end{array}$ & Several per year & 4 per year \\
\hline $\begin{array}{l}\text { Bus or transmission } \\
\text { line fault }\end{array}$ & Short-circuit & $\begin{array}{l}\text { Bus structure or transmission } \\
\text { line } \\
\text { Capacitors } \\
\text { Damping resistors }\end{array}$ & $\begin{array}{l}\text { Several during facility } \\
\text { lifetime }\end{array}$ & 0 \\
\hline
\end{tabular}

70-50-0595-1327pb01

\section{Test Bed}

A power conditioning test-bed was constructed to investigate fault tolerance and other NIF capacitor module design issues. The test-bed uses 36 capacitors that each store $52 \mathrm{~kJ}$ for a total of $1.9 \mathrm{MJ}$ at $22 \mathrm{kV}$. The capacitors are surplus from the Beamlet ${ }^{2}$ power conditioning system and exhibit the self-healing characteristics of a metallized dielectric system similar to those planned for the NIF. Although the Beamlet capacitors are rated for only $22 \mathrm{kV}$, they can operate, with reduced lifetime, at the $23.5 \mathrm{kV} \mathrm{NIF}$ operating point to simulate full power 
operation. The test-bed, shown in the photograph of Figure 4 (top photo) is arranged to electrically simulate the NIF module. In addition to fault tolerance, the test-bed is used to test other pulsed power components and issues including transmission lines, charging supplies, mounting structures, flashlamp triggering, assembly methods and other fault modes.

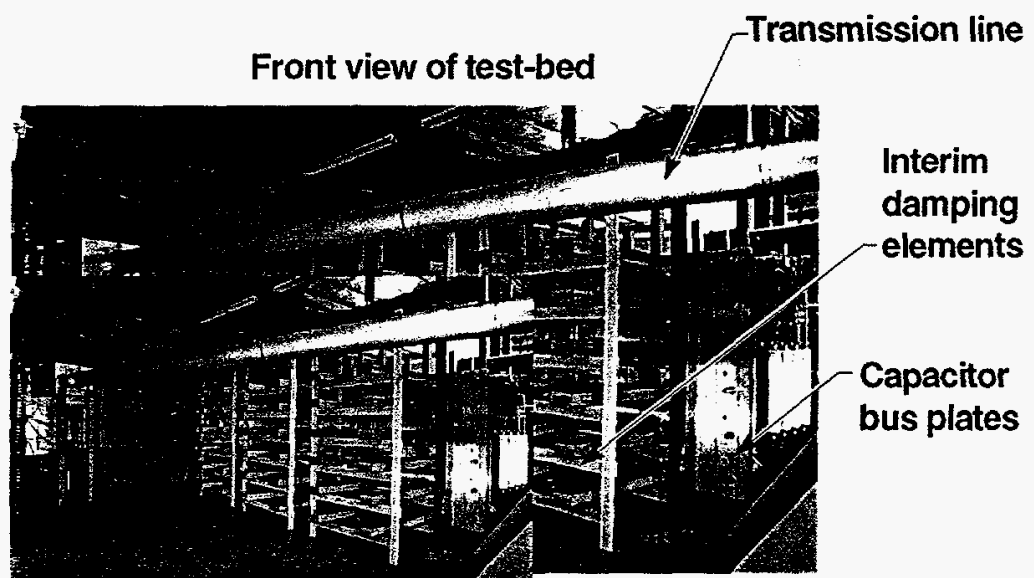

Side/rear view of teșt-bed

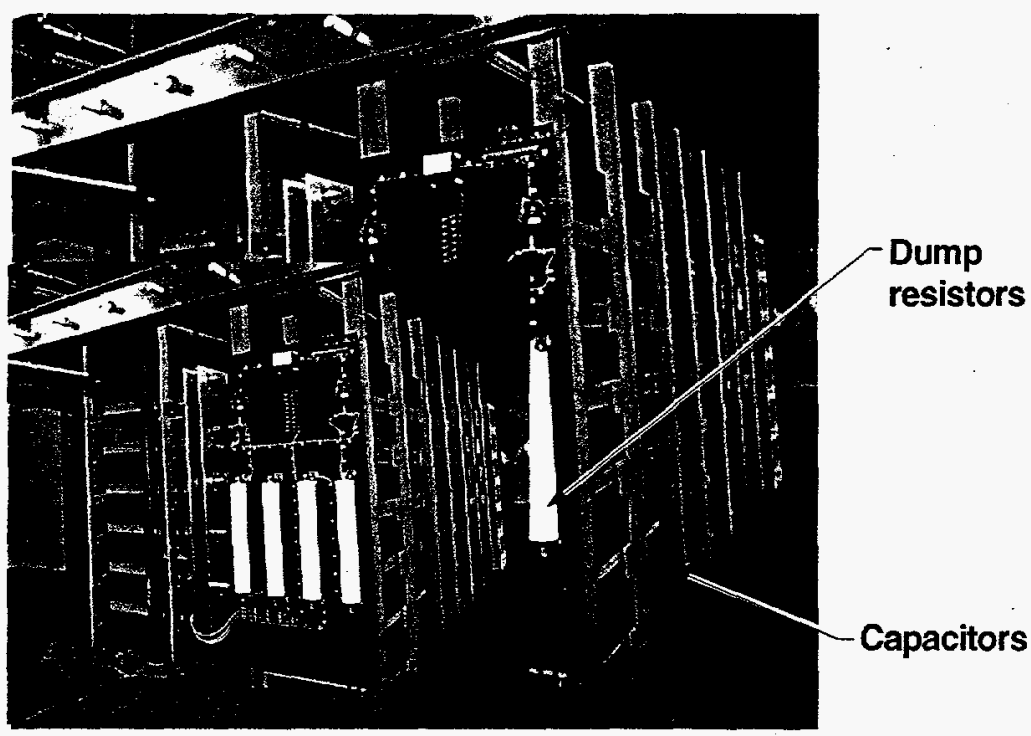

70-50-0595-1329pbo 1

Detailed measurements have been made using the test-bed in three configurations: capacitor fault with a resistive damping element, capacitor fault with a resistive and inductive damping element, and bus fault. The experiments have been performed at low voltage (1-3 kV) because of limitations of the existing damping element design. A resistive and inductive element is planned for the NIF module, however only the prototype was available for these measurements. Figure 5 illustrates the locations of detailed capacitor current measurements in the $6 \times 6$ capacitor array, and of the capacitor and bus faults. 
I indicates location

of a fault current

measurement

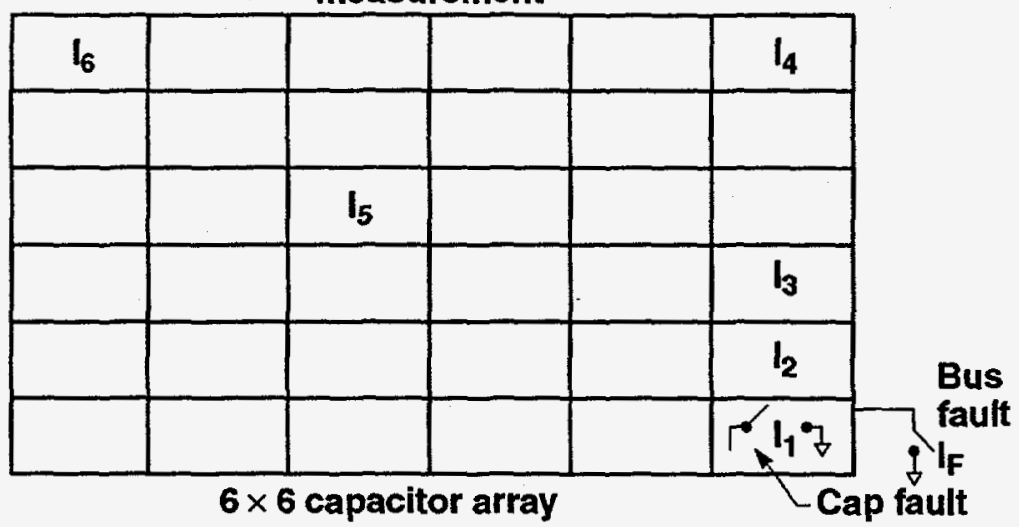

70-50-0595-1332pb01

\section{Modeling and Results}

A detailed SPICE model is used to explore a larger parameter space than is possible with the test-bed. Current and voltage measurements from the test-bed are used to refine and validate the SPICE model. The model is then modified to account for the differences between the test-bed and the NIF module design. The model can then be used to predict the NIF module performance, and to optimize the circuit values to enhance the fault tolerance of the design. The waveforms of Figure 6 modified to distinguish waveforms in black-and-white) demonstrate good agreement between the test-bed and model results for the bus fault and capacitor fault with inductive damping element cases. The model accurately replicates features on the waveforms caused by the distributed inductance of the capacitor bus plates.

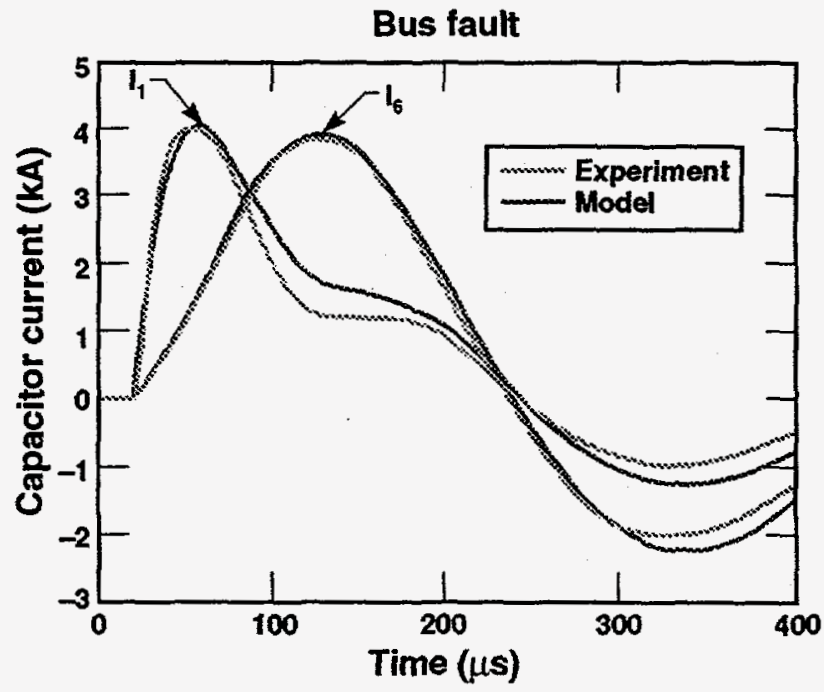

Capacitor fault with inductive damping element

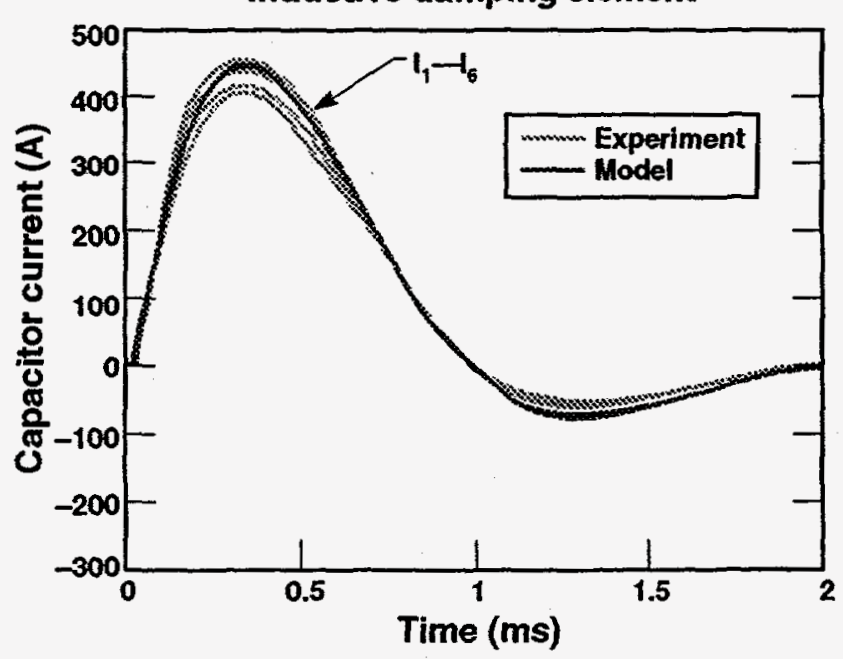

70-50-0595-1333pb01 
In order to predict the NIF module performance, the test-bed model is modified to account for the different capacitor values and physical layout of the NIF design. An example of the network used to simulate the capacitor fault case is shown in Figure 6

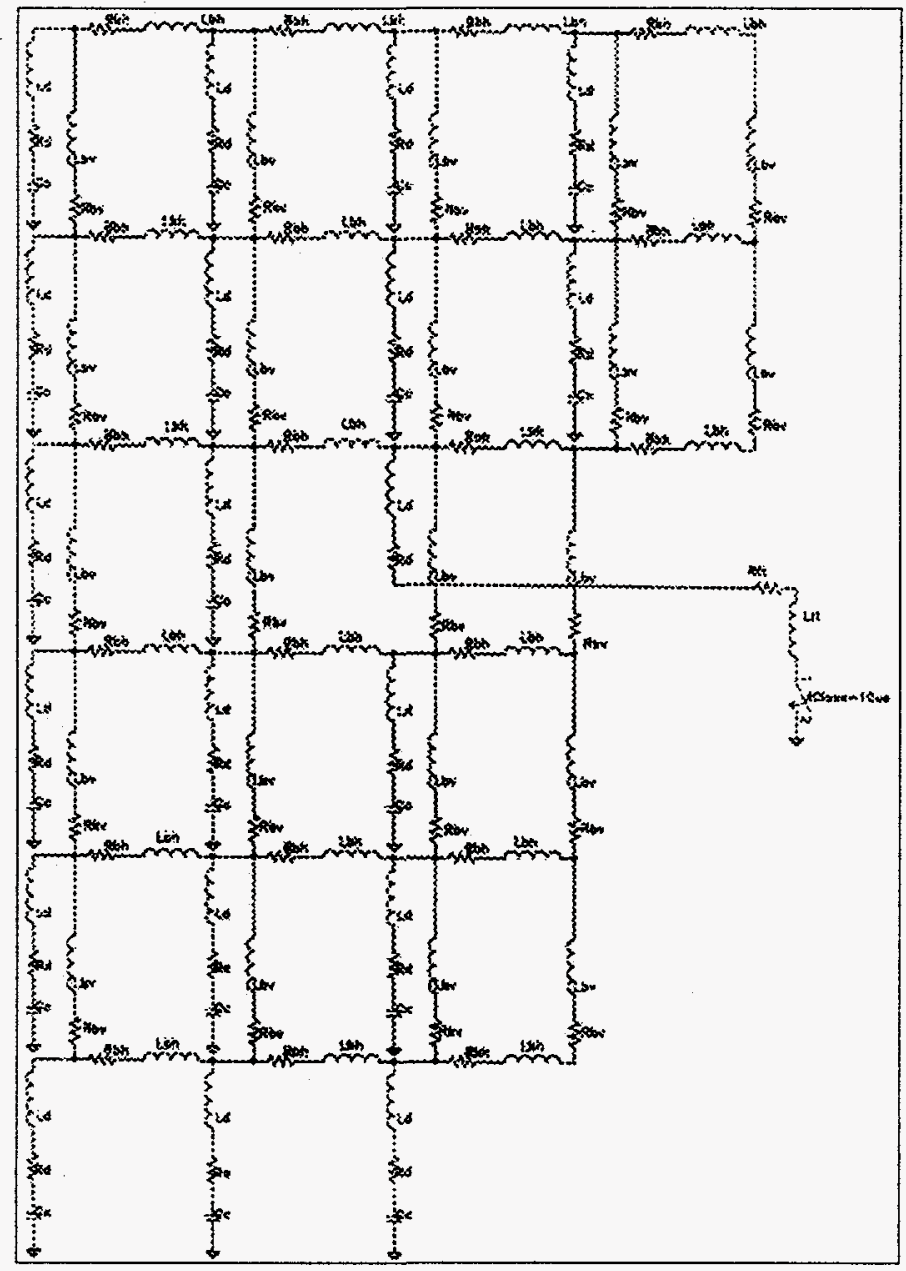

70-50-0595-1331pbot

The total circuit inductance and resistance are defined by the amplifier pulse width and system transfer efficiency requirements. However, some flexibility in distributing the total inductance and resistance budgets may be exercised in order to maximize system fault tolerance. Parametric analyses using the SPICE model are performed for this purpose. The results, shown in Figures 7,8 and 9 illustrate worst-case fault current as a function of the ratio of circuit inductance and resistance in the ballast inductors and capacitor damping elements. 
Flashlamp fault
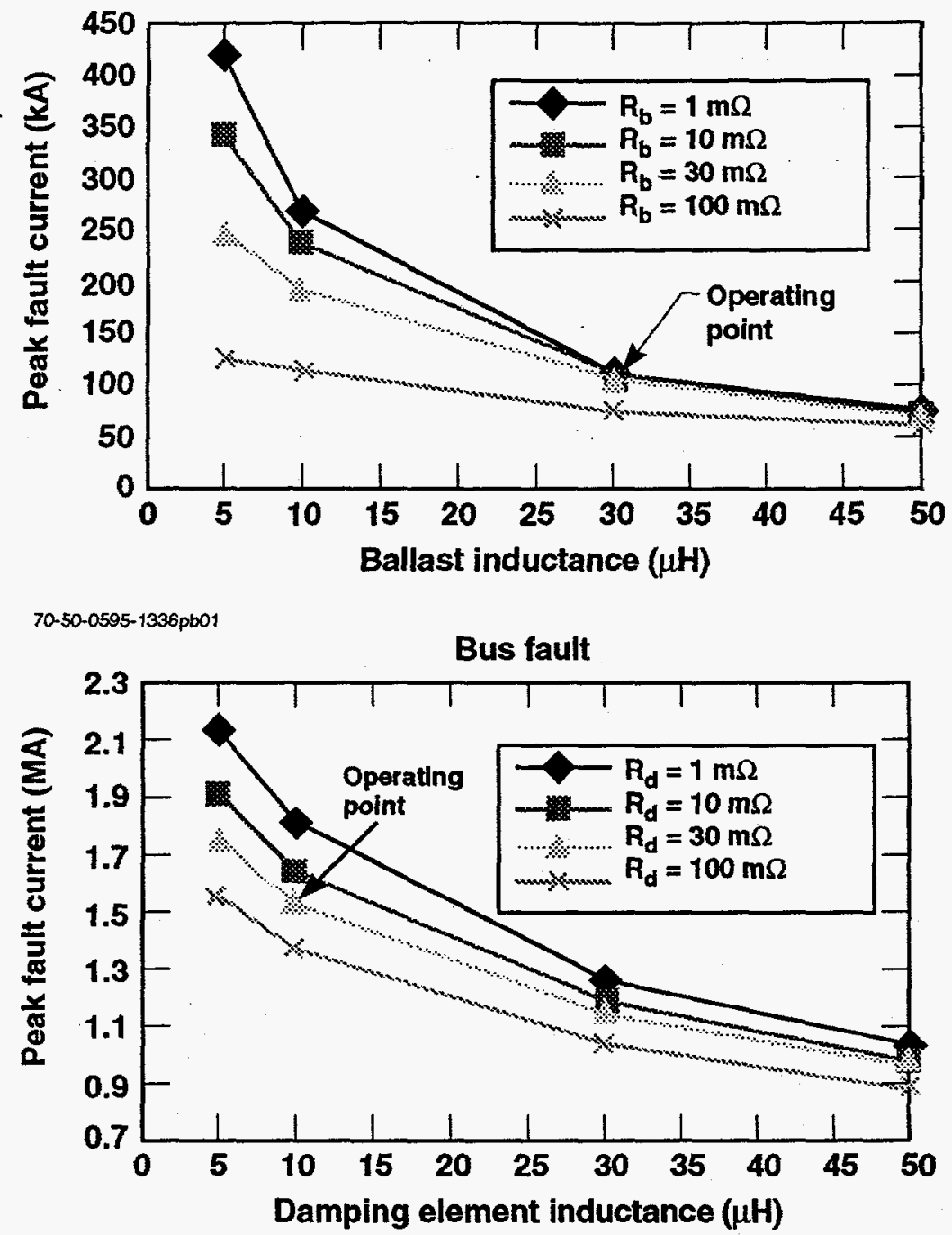

70-50-0595-1336pb03

Capacitor fault

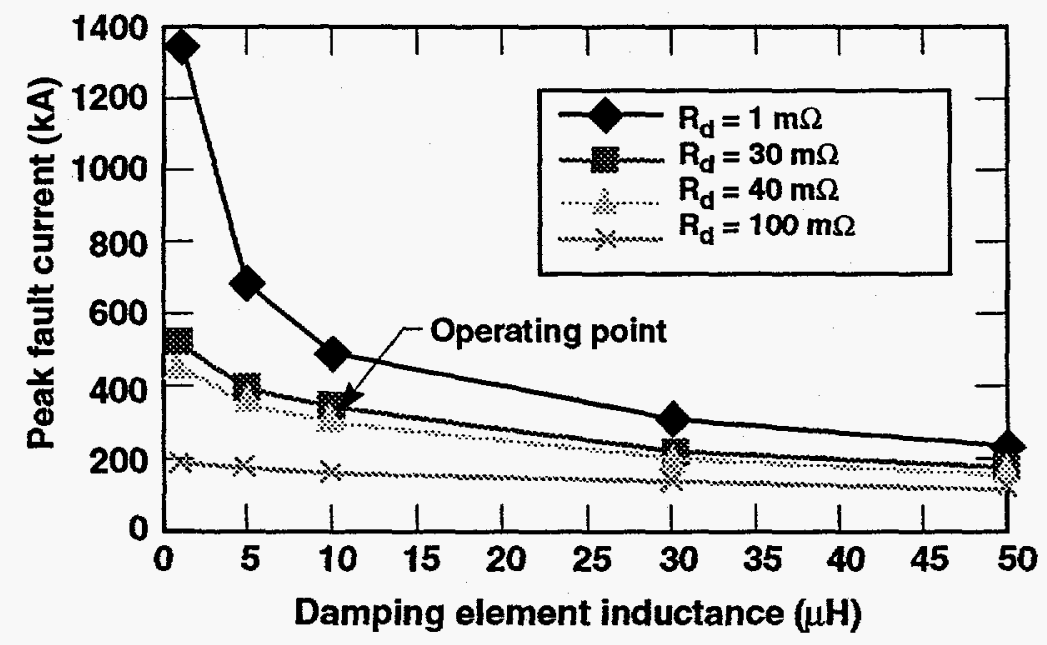

70-50-0595-1336pbo2 
These plots show that it is clearly desirable to place as much of the budgeted inductance and resistance as possible at the "two ends" of the system, e.g. at the capacitors and flashlamps, therefore minimizing the impedance of the transmission line and switch. Careful inspection of the plots also shows that resistance is more effective at limiting fault current at the capacitors than at the flashlamps for reasonable values of ballast inductance. The plots are used to select values of inductance and resistance for the damping and ballast elements as shown in the budgets of Table 2 .

\begin{tabular}{|l|r|c|}
\hline \multicolumn{1}{|c|}{ Component } & Inductance $(\mu \mathrm{H})$ & Resistance $(\mathrm{m} \Omega)$ \\
\hline \hline Capacitor damping resistor & $10 / 20_{\mathrm{ea}}=0.5$ & $40 / 20_{\mathrm{ea}}=2$ \\
\hline Transmission line & 0.5 & 1.5 \\
\hline Ballast inductors & $30 / 20_{\mathrm{ea}}=1.5$ & $20 / 20_{\mathrm{ea}}=1$ \\
\hline Misc. bus and switches & 0.2 & 0.7 \\
\hline \hline Total & 2.7 & 5.2 \\
\hline
\end{tabular}

$70-50-0595-1334 \mathrm{pbo} 1$

The selected circuit values are used by the model to calculate the worst-case current in the critical components during fault modes of interest. The results, tabulated in Table 3 show that the values are within the ratings of available components in most cases. Two cases are identified which require additional development. The $300 \mathrm{kA}$ current flowing in the damping resistor during a short-circuit of the corresponding capacitor will likely cause permanent damage, and this element will be replaced after such an event. Additional tests will validate adequate performance of this component during full-energy faults. The second issue identified is the fault current flowing in the bus or transmission line during a short-circuit bus fault. The 1.6 MA peak current may result in forces which exceed the material strength for reasonable methods of force-bracing. Additional analysis and force-bracing design work will resolve this issue. Since the expected frequency of this type of fault is very low, a reasonable solution might be to allow the bus to fail (non-catastrophically) and replace the damaged hardware after the fault.

\begin{tabular}{|c|c|c|c|c|c|}
\hline \multirow[b]{2}{*}{ Fault mode } & \multicolumn{4}{|c|}{ Fault current in: } & \multirow[b]{2}{*}{$\begin{array}{l}\text { Expected } \\
\text { frequency }\end{array}$} \\
\hline & $\begin{array}{l}\text { Damping } \\
\text { resistor (KA) }\end{array}$ & $\begin{array}{c}\text { Ballast } \\
\text { inductor (kA) }\end{array}$ & $\begin{array}{c}\text { Bus/T-line } \\
\text { (KA) }\end{array}$ & $\begin{array}{c}\text { Capacitor } \\
\text { (kA\% \% reversal) }\end{array}$ & \\
\hline Flashlamp & 27 & 100 & 530 & $27 / 0 \%$ & Several per year \\
\hline Capacitor & 800 & - & - & $16 / 18 \%$ & Several per year \\
\hline Bus & 83 & - & 1600 & $83 / 60 \%$ & $\begin{array}{l}\text { Several during } \\
\text { facility lifetime }\end{array}$ \\
\hline
\end{tabular}




\section{Conclusions}

The fault-tolerance of the low-cost NIF pulsed power circuit approach has been investigated with a combination of experiments and modeling. A test-bed was used to validate a SPICE circuit model. The model was used to perform parametric analyses which enable an optimum distribution of the budgeted inductance and resistance. The resulting predicted fault current values were then used to determine the required ratings of system components and identify areas requiring further development.

\section{Acknowledgments}

*Work performed under the auspices of the U.S. Department of Energy by Lawrence Livermore National Laboratory under Contract No. W-7405-Eng-48. 